\title{
Effect of Rye and Mix Cover Crops on Soil Water and Cotton Yield in a Humid Environment
}

\author{
José O. Payero ${ }^{1 *}$, Michael W. Marshall ${ }^{1}$, Rebecca H. Davis ${ }^{1}$, Joe Bible ${ }^{2}$, Nathaniel Nemire ${ }^{2}$ \\ ${ }^{1}$ Edisto Research and Education Center, Clemson University, Blackville, SC, USA \\ ${ }^{2}$ School of Mathematical and Statistical Sciences, Clemson University, SMSS, Clemson, South Carolina, USA \\ Email: *jpayero@clemson.edu
}

How to cite this paper: Payero, J.O., Marshall, M.W., Davis, R.H., Bible, J. and Nemire, N. (2021) Effect of Rye and Mix Cover Crops on Soil Water and Cotton Yield in a Humid Environment. Open Journal of Soil Science, 11, 271-284. https://doi.org/10.4236/ojss.2021.115015

Received: April 27, 2021

Accepted: May 28, 2021

Published: May 31, 2021

Copyright ( 2021 by author(s) and Scientific Research Publishing Inc. This work is licensed under the Creative Commons Attribution International License (CC BY 4.0).

http://creativecommons.org/licenses/by/4.0/ (c) (i) Open Access

\begin{abstract}
In recent years, the use of cover crops is becoming a popular technology among growers in many regions of the United States, which is expected to deliver various benefits such as improving soil health, increasing soil organic matter, controlling weeds, and helping conserve soil water and nutrients. Although expecting these benefits seems reasonable, it is challenging to know how much of these benefits to expect under specific situations. The potential effect of cover crops on soil water conservation is especially significant because of the documented impact of soil water on crop yield, especially for dryland cropping systems. Some researchers have found that planting a cover crop tended to increase soil water, while others have reported the opposite effect. Information on the impact of cover crops on soil water in cotton (Gossypium hirsutum L.) production systems in South Carolina is currently lacking. Therefore, the objective of this study was to quantify the effect of cover crops on soil water and cotton yield. A field experiment was conducted in South Carolina during winter, spring, and summer of 2015, with three cover crop treatments. The treatments included: 1) rye (Secale cereale L.), planted alone; 2) a mix of six cover crop species; and 3) a control treatment with no-cover. The cover crop was established in the winter, terminated in the spring, and cotton was grown during the summer. Soil water was measured at different depths using capacitance probes and a neutron probe. Our results showed no significant differences in soil water and cotton yield among the cover crop treatments. These results suggest that under the humid conditions of this study, any short-term effect of the cover crop on soil water was masked by timely rain.
\end{abstract}

\section{Keywords}

Soil Moisture, Soil Water, Cover Crop, Cotton, Sensors 


\section{Introduction}

Planting a cover crop rather than leaving the land fallow during the winter is an agronomic practice that has long been promoted since it offers several potential benefits to the soil and the cash crop. Some of these potential benefits include the effect of cover crop on increasing soil organic carbon and carbohydrates [1], supplying soil Nitrogen [2], stabilizing soil temperature [3], suppressing weeds [4] [5], increasing crop yield [6], conserving soil moisture [7], reducing runoff and soil erosion [8], and increasing water use efficiency [9], among other potential benefits. Because of its direct impact on crop yield, one of the most economically significant potential benefits of planting a cover crop is its effect on conserving soil water. However, there is disagreement in the literature about the impact of cover crops on soil water conservation. Some researchers have reported a net gain in soil water due to planting a cover crop, while others have found the opposite.

Examples of researchers who have found that cover crops tended to increase soil water include Karukua et al. [10], who compared the effect of cover crop residue in soil moisture in tomato production. They found that the cover crop increased moisture storage, leading to increased tomato yields and water use efficiency. Similarly, Wells et al. [5] evaluated the effect of rye cover crop on soil moisture in soybean production. They found that soil moisture was higher in cereal rye mulch treatments compared to a control treatment. Acharya et al. [11] reported that cover crops increased soil moisture in the top $30 \mathrm{~cm}$ soil depth by $3 \%$ to $5 \%$ compared to control plots. Stipešević and Kladivko [3], evaluating the effect of winter wheat cover crop in corn production, found that the cover crop increased soil moisture due to its mulching effect. Clark et al. [12] also found that soil moisture in the $20 \mathrm{~cm}$ soil depth when growing a cover crop was greater than or equal to the no-cover controls throughout the spring and the summer. Daigh et al. [13] observed that during the 2012 drought in Iowa and Indiana, planting a rye cover crop either had no impact or significantly increased soil water.

On the other hand, Mitchell et al. [7] reported that cover crops tended to decrease soil water. They found that cover crop biomass production may come at the cost of soil water depletion in a semiarid, drought-prone region of California. Similarly, Liebl et al. [4], in a four-year study with rye cover crop in Illinois, found that soil water content was the lowest in June under the late-killed rye (killed at planting) during dry periods due to water depletion caused by the growing rye. McGuire et al. [14], comparing winter legume cover crop vs. fallow for wheat production, showed that more soil water depletion occurred with the cover crop than in fallow. They also found that heavy rains eliminated any detrimental effect on the following wheat crop during the winter. Kahimba et al. [15] found that a cover crop treatment significantly reduced soil moisture during the growing season. Krueger et al. [16] found that the soil moisture after rye killed three to four weeks before planting corn was similar to a control treat- 
ment, but soil moisture after rye harvested two days before corn planting was $16 \%$ lower than the control.

Similarly, Ruiz-Colmenero et al. [8] showed that the cover crop treatment reduced soil moisture during a vineyard's vegetative period compared to soils with traditional tillage. They found that although the transpiration through the permanent cover crop was offset by increased infiltration, the cover crop competed actively for water and resulted, on average, in $40 \%$ lower grape yields. Meyer et al. [17] used long-term simulation modeling to compare cover crops to a bare-soil control. They found that cover crops could significantly reduce soil water content ( 0 - $120 \mathrm{~cm}$ deep) for the following cash crop by a mean of $20-50$ $\mathrm{mm}$, and up to $80 \mathrm{~mm}$ in dry spring conditions. Still, early termination of the cover crop could decrease this negative impact. Thus, they suggested destroying cover crops in late autumn and retaining the residues as mulch to take advantage of the multiple services the cover crops provide during the fallow period while avoiding the negative impact on soil water availability for the following cash crop. In South Carolina, information on the effect of cover crops on soil water in cotton cropping systems is currently lacking. Therefore, the objective of this study was to quantify the impact of winter cover crops on soil water and cotton yield.

\section{Methods}

\subsection{Field Experiment and Data Collection}

The field experiment for this study was conducted in 2015 at the Clemson University Edisto Research and Education Center (EREC) near Blackville, SC. The experimental field was $130 \mathrm{~m} \times 110 \mathrm{~m}$ and had a Barnwell loamy sand $(\mathrm{DaB})$ soil [18]. The typical soil profile for the Barnwell loamy sand soil has a loamy sand layer in the top $0-20 \mathrm{~cm}$ depth and a sandy clay loam layer in the $20-200 \mathrm{~cm}$ depth. The research site was located in the humid southeast USA region with average annual precipitation of $1198 \mathrm{~mm}$, and maximum and minimum air temperatures of $25.6^{\circ} \mathrm{C}$ and $11.7^{\circ} \mathrm{C}$, respectively [19].

The field experiment compared three cover crop treatments using a completely randomized design with four replications. The treatments included: 1) rye planted alone; 2) a mix of six cover crop species; and 3) a control treatment with no-cover. These treatments will be referred to as "Rye," "Mix," and "None," respectively. The Mix treatment included rye (56.7\%), oats (14.1\%), turnip (3.45\%), vetch (7\%), radish (3.45\%), and crimson clover (14.1\%). The cover crop was planted in the winter $(1 / 16 / 2015)$ and was terminated in the spring using herbicides and the residue was rolled using a tractor-mounted roller (Landoll Company, Marysville, KS). Cotton was planted on 5/17/2015 in the field during the summer following the cover crop.

Soil volumetric water content (VWC) during the cover crop and cotton growth periods were measured at different depths using capacitance soil moisture sensors and a neutron probe. $\mathrm{ECH}_{2} \mathrm{OEC}-5$ capacitance moisture sensors 
(METER Environment, Pullman, WA) were installed at 15, 30, 45, and $60 \mathrm{~cm}$ soil depths at the center of each experimental plot. The $\mathrm{ECH}_{2} \mathrm{O}$ EC-5 sensors determine VWC by measuring the dielectric constant of the media using capacitance/frequency domain technology. Em50R wireless radio data loggers (METER Environment, Pullman, WA) were used to automatically read the sensors and store the VWC data every hour. Neutron probe tubes were also installed in each plot to measure VWC using the neutron scattering method [20]. The neutron probe VWC was measured weekly using a CPN Hydroprobe ${ }^{\mathrm{TM}}$ (CNP, Raleigh, NC) from five soil depths $(15,30,45,60$, and $76 \mathrm{~cm})$.

Plant samples were collected from each plot on $4 / 23 / 15$ to determine the dry biomass production from the planted cover crops and the weeds that grew in the control treatment. For the Mix treatment, the plant samples were also divided to determine the biomass production for each of the six cover crop species included in the cover crop mix (rye, oats, turnip, vetch, radish, and crimson clover). Yield from the cotton plots was also measured using a cotton picker equipped with a yield monitor. Figure 1(a) shows the established cover crop and control plots, and Figure 1(b) shows the same plots just before cover crop termination in the spring. Figure 1(b) also illustrates the significant amount of weed pressure in the control plots. Figure 2(a) shows one of the soil moisture measurement setups, including the $\mathrm{ECH}_{2} \mathrm{O}$ EC-5 sensors connected to an Em50R data logger in one of the plots. Figure 2(b) shows the cotton planted after the cover crop was
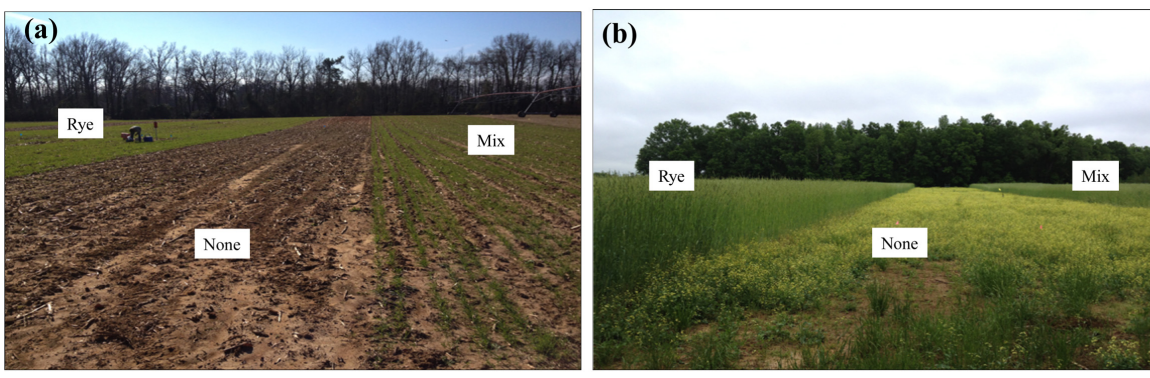

Figure 1. (a) Established cover crop and control plots, and (b) Cover crop fully-grown and weeds growing in the control plot.

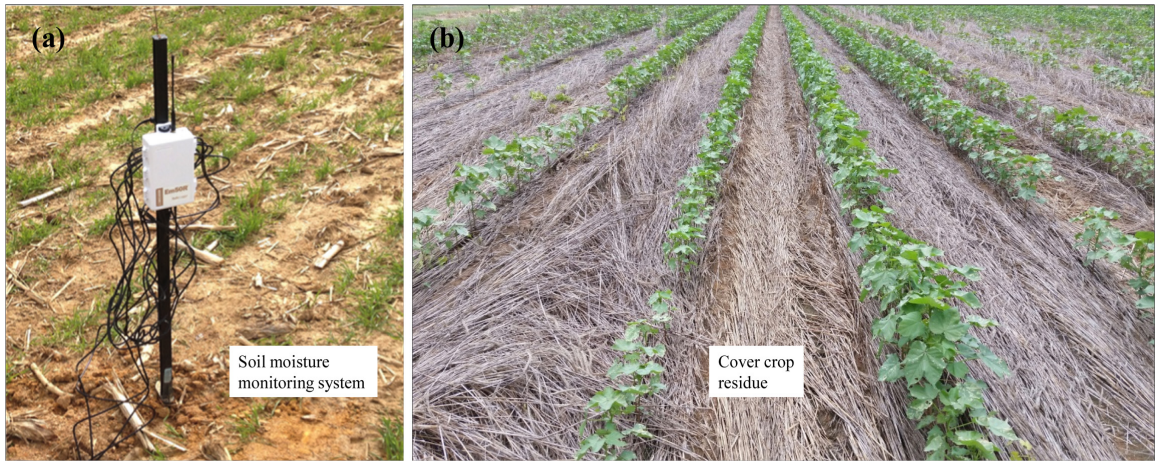

Figure 2. (a) Field setup to measure soil moisture in one of the experimental plots, and (b) Cotton planted after cover crop, showing cover crop residues between the cotton rows. 
terminated, showing the plant residue mulch remaining from the cover crop. Daily weather data for 2015 was obtained from an electronic weather station operated by NOAA, which is located within the EREC research farm.

\subsection{Statistical Analyses}

\subsubsection{Analysis of $\mathrm{ECH}_{2} \mathrm{O}$ EC-5 Sensors VWC Data}

The statistical analysis of the VWC data from the $\mathrm{ECH}_{2} \mathrm{O}$ EC- 5 sensors focused on the average soil moisture (ASM), which was calculated as the arithmetic average of the four depths' daily VWC. Two types of analyses were conducted for ASM from the $\mathrm{ECH}_{2} \mathrm{O}$ EC-5 sensors, focusing on mean daily soil moisture loss (EC5_ASMLoss), which was the difference between the current ASM and the ASM measured the day before. In the first analysis, the mean daily moisture loss was modeled, stratifying by season (cover crop season vs. cotton season) and controlling for new daily infiltration. In the second analysis, the daily moisture loss was modeled, stratifying by month and controlling for new daily infiltration. Data from January and May were excluded from analysis since these months represented transitional periods in crop establishment and soil moisture data collection. Both types of analyses employed a repeated-measures conditional-means model (controlling for daily new infiltration) where the mean square for error was taken from the observed between-plot variation. All analyses were conducted in R 3.6.2 [21] on a Windows 10 platform (the code for conducting analyses is available upon request). In both sets of analyses, the fitted models were of the form,

$$
\text { EC5_ASMLoss }{ }_{i j k}=\mu+\text { Treat }_{i}+\text { Infiltration }_{i j k} \times \beta+\text { Day }_{i j k}+\text { Plot }_{k}
$$

where, $\operatorname{Day}_{i j k} \sim N\left(0, \sigma_{d}^{2}\right)$, Plot $_{k} \sim N\left(0, \sigma_{\epsilon}^{2}\right)$, and $\mu$ correspond to the average soil moisture loss across all days and plots, and $\beta$ is a correction factor to accommodate the effect of new daily infiltration on moisture loss. The quantities

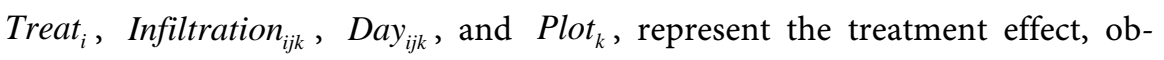
served daily infiltration, treatment/day/plot specific effect, and plot-specific variation, respectively. In each analysis, the data were subset according to records belonging to the desired growing season or months, and individual models were fitted to the data belonging to each stratum.

\subsubsection{Analysis of Neutron Probe VWC Data}

The neutron probe daily soil moisture loss (NP_ASMLoss) data were analyzed using the average soil volumetric water content (VWC) calculated as the arithmetic average of four depths. Because of the frequency of data collection with the neutron probe, we could not conduct the analysis on the average daily moisture loss. Instead, the data analysis focused on mean VWC stratifying by month and growing season (cover crop season or cotton season). In both analyses, the data were stratified according to whichever month/season was of interest, and the following model was fitted:

$$
\text { NP_ASMLoss }{ }_{i j k}=\mu+\text { Treat }_{i}+\text { Day }_{i j k}+\text { Plot }_{k}
$$


where, $\operatorname{Day}_{i j \mathrm{j}} \sim N\left(0, \sigma_{d}^{2}\right), \operatorname{Plot}_{k} \sim N\left(0, \sigma_{\epsilon}^{2}\right)$. All error calculations were made using the between-plot variation i.e. $\sigma_{\epsilon}^{2}$.

\subsubsection{Analysis of Cotton Yield and Cover Crop Biomass Data}

The analyses of the cotton yield and cover crop biomass were conducted using the following models:

$$
\begin{gathered}
\text { CottonYield }=\mu+\text { Treat }_{i}+\text { Plot }_{k} \\
\text { CoverCropBiomass }=\mu+\text { Treat }_{i}+\text { Plot }_{k}
\end{gathered}
$$

where, Treat $_{i}$ represents the cover crop treatment effect, and $\operatorname{Plot}_{k} \sim N\left(0, \sigma_{\epsilon}^{2}\right)$, the plot-specific variation. A Tukey's comparison was conducted to compare means amongst the three treatments.

\section{Results and Discussion}

\section{1. $\mathrm{ECH}_{2} \mathrm{O}$ EC-5 Sensors Data}

The hourly VWC data are presented in Figure 3 . They were collected from four soil depths using the $\mathrm{ECH}_{2} \mathrm{O}$ EC-5 sensors installed in one of the control plots (plot CC105). Figure 4 illustrates the data included for ASM analyses. The top, middle, and bottom panels panel correspond to the daily ASM values for the plots in the Mixed, None (no cover), and Rye treatments, respectively.

The results of the by-season and by-month analyses of ASM are presented in Figure 5 and Table 1. Due to the scale of the day-over-day differences in ASM, all values were presented as percentages rather than on the original ratio scale. Results of the by-Season Analysis, including the fitted means and associated confidence intervals, are shown in the top panel of Figure 5 and the first block of rows in Table 1 . We observed that treatment did not significantly impact the mean moisture loss after controlling for daily infiltration. The furthest left point at the top-left panel of Figure 5 indicates that the mean percent ASM loss for the mixed cover crop plots during the cover crop season was -0.25 with a $95 \%$ confidence interval of -0.28 to -0.22 . These results mean that we expected the

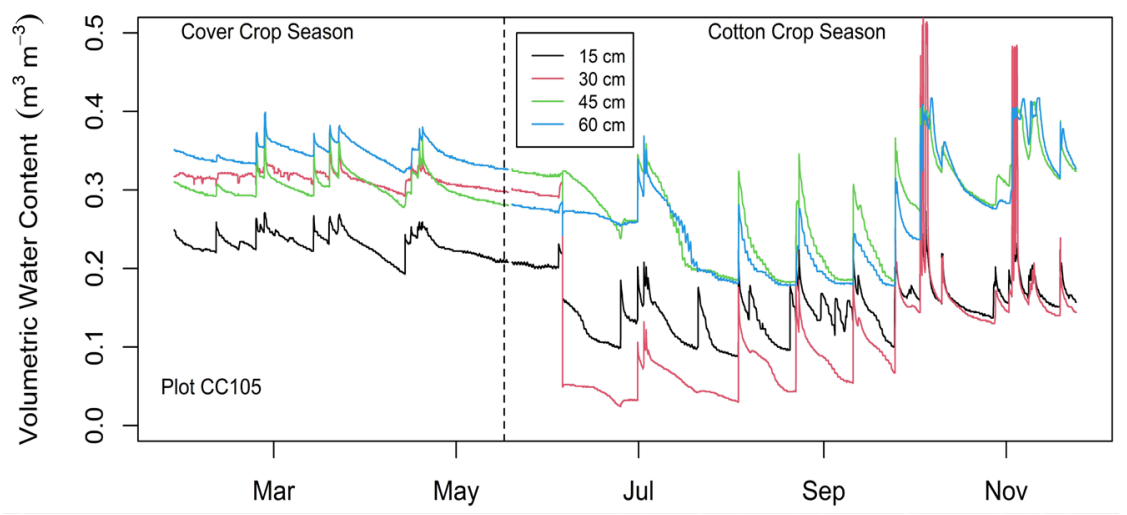

Figure 3. Volumetric water content (VWC) measured with $\mathrm{ECH}_{2} \mathrm{O}$ EC-5 sensors at four depths on a cotton plot (plots \# CC105) during the cover crop and cotton growing season in 2015. The plot did not have a cover crop during the off-season. The vertical line represents the cotton planting date. 

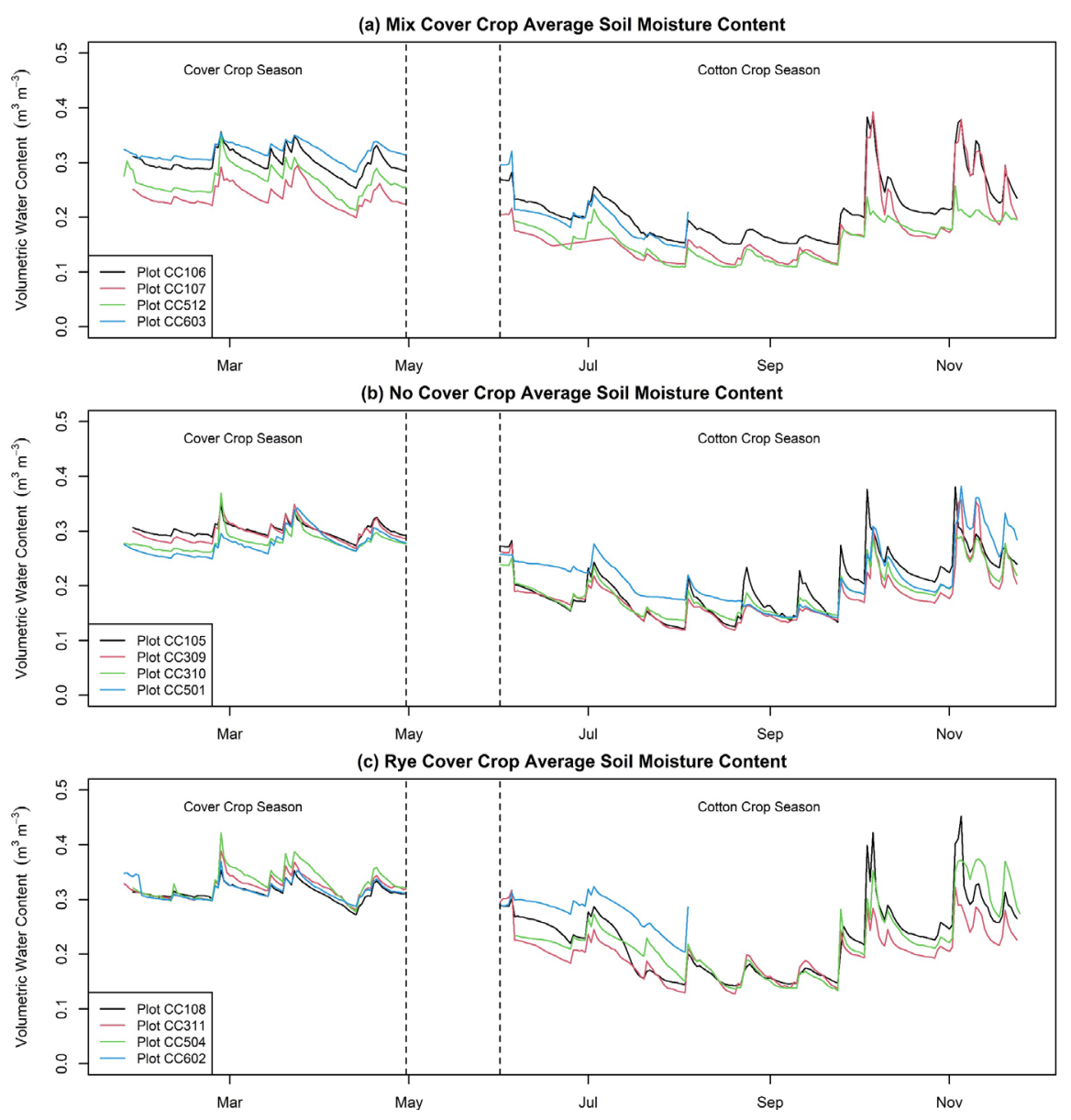

Figure 4. Average soil moisture (ASM) measured as the arithmetic average of measured soil moisture at four depths. The top panel corresponds to the daily ASM measurements for each of the plots in the Mix cover crop treatment. The middle panel presents the same for the control (no cover crop) treatment. The lower panel illustrates the daily ASM for the plots in the rye cover crop treatment.

percent ASM loss to decrease daily for Mix cover crops by -0.25 with the corresponding confidence interval.

Similarly, the furthest right point (in the top panel) indicates that the mean ASM loss for the rye cover crop during the cotton season was -0.52 with a $95 \%$ confidence interval of -0.66 to -0.39 . It is worth noting that none of the treatments differed significantly within seasons with respect to the mean percent ASM loss. While the confidence interval for the Mix crop did not overlap with the confidence intervals for the rye and None treatments during the cover crop season, the discrepancy between the mean percent ASM loss can hardly be considered significant from a practical standpoint.

For the by-month analyses, we observed similar results that are summarized graphically in the bottom panel of Figure 5 and the lower block of rows in Table 1. The bottom panel of Figure 5 shows that the furthest-right point corresponds to the mean percent ASM loss for the rye cover crop group during August with a value of -1.23 and a corresponding $95 \%$ confidence interval (CI) of -1.58 to 


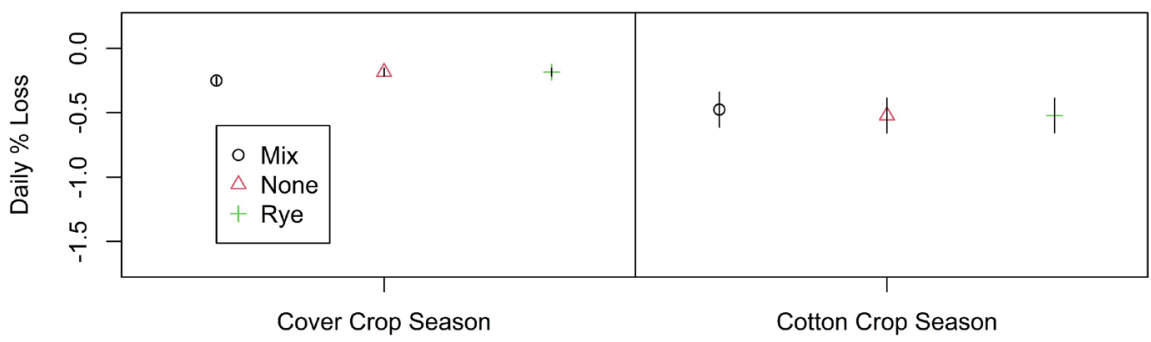

(b) Mean Daily Average Soil Moisture Loss

by Month

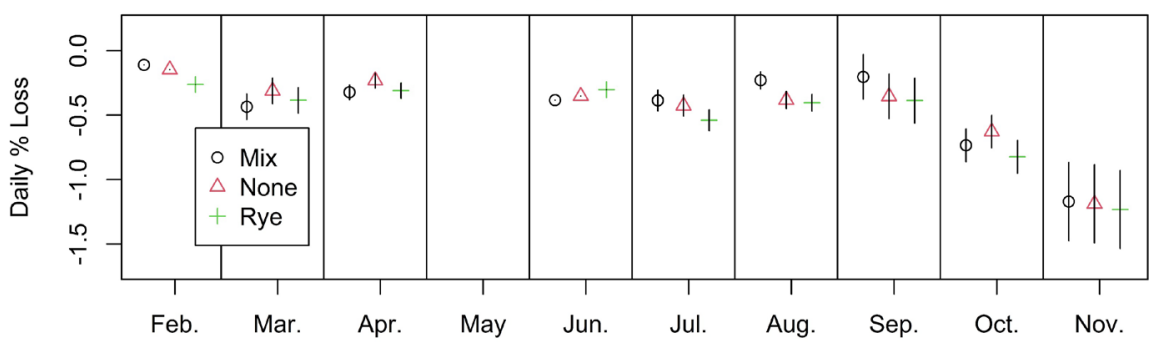

Figure 5. Means plots by cover crop treatment, stratifying by cover crop season (Cover vs. Cotton), and by month. The location of the symbols indicates the point estimate for the mean \% ASM loss, and the vertical segments demonstrate a 95\% confidence interval for the estimate. Note that within February and June, there was not enough between-plot variation for these months to accurately estimate the error, as such confidence intervals are not reported for these months.

Table 1. Estimated mean percent ASM loss. Results are presented for each cover crop type and stratified by cover crop season (Cover Crop vs. Cotton) and month (excluding January and March).

\begin{tabular}{lccc}
\hline \multicolumn{4}{c}{ Mean Percent Average Soil Moisture Loss } \\
\hline \multicolumn{4}{c}{ By Season } \\
\hline Season & Mix & None & Rye \\
\hline Cover Crop & $-0.25(-0.28,-0.22)$ & $-0.18(-0.21,-0.15)$ & $-0.18(-0.21,-0.15)$ \\
Cotton & $-0.48(-0.61,-0.34)$ & $-0.52(-0.66,-0.39)$ & $-0.52(-0.66,-0.39)$ \\
\hline & & By Month & Rye \\
\hline Month & Mix & None & $-0.26\left(^{*}\right)$ \\
\hline Feb. & $-0.11\left(^{*}\right)$ & $-0.15\left(^{*}\right)$ & $-0.38(-0.5,-0.27)$ \\
Mar. & $-0.43(-0.55,-0.32)$ & $-0.31(-0.43,-0.20)$ & $-0.31(-0.38,-0.24)$ \\
Apr. & $-0.32(-0.39,-0.26)$ & $-0.23(-0.30,-0.17)$ & $-0.30\left(^{*}\right)$ \\
Jun. & $-0.38\left(^{*}\right)$ & $-0.35\left(^{*}\right)$ & $-0.54(-0.63,-0.45)$ \\
Jul. & $-0.39(-0.48,-0.29)$ & $-0.43(-0.52,-0.33)$ & $-0.40(-0.48,-0.33)$ \\
Aug. & $-0.23(-0.31,-0.15)$ & $-0.38(-0.46,-0.31)$ & $-0.39(-0.59,-0.19)$ \\
Sep. & $-0.20(-0.40,0.00)$ & $-0.35(-0.55,-0.15)$ & $-0.82(-0.97,-0.68)$ \\
Oct. & $-0.73(-0.88,-0.59)$ & $-0.63(-0.78,-0.48)$ & $-1.23(-1.58,-0.88)$ \\
Nov. & $-1.17(-1.52,-0.82)$ & $-1.19(-1.54,-0.84)$ & \\
\hline & & & \\
\hline
\end{tabular}


-0.88 . It is worth noting that, like in the by-season analyses, the Mix cover crop had marginally non-overlapping interval with the other two cover crop types $(-0.31$ to -0.15 vs. $-0.46,-0.31$ and $-0.48,-0.33$ for None and rye cover crop, respectively). However, this was only observed during August and, as such, should not be over-interpreted. In all, we observed no consistent differences in moisture retention when stratifying by-season or by-month.

\subsection{Neutron Probe Data}

The results from the neutron probe ASM data analyses, both by-season and by-month, are shown in Table 2 and Figure 6 . The by-month results in Table 1 show that in February, the mean soil moisture for the Mix cover crop plots was 0.28 with a corresponding confidence interval $(0.26,0.31)$. The related point in Figure 6 can be found in the bottom panel (black circle and associated line segment illustrating the $95 \% \mathrm{CI}$ ) furthest point to the left. It shows that the rye cover crop had almost consistently (excepting September) the highest average soil moisture. However, when considered in contrast to the expected margins of error, the observed soil moistures offer only marginal evidence that the rye cover crop may increase average soil moisture.

\subsection{Cover Crop Biomass and Cotton Yield Production}

\subsubsection{Cover Crop Biomass Production}

The average biomass production for the Mix, Rye, and None treatments was 4138, 4941, and $1791 \mathrm{~kg} / \mathrm{ha}$, respectively. Figure 7(a) showed no significant difference in biomass production between the Mix and Rye cover crop treatments,

Table 2. Mean average soil moisture (95\% CI) as measured by neutron probe. Means are presented stratifying by month and cover crop season (note that May was excluded due to cotton crop planting, and there were no neutron probe measurements in June). ${ }^{*}$ denotes that there was not enough between plot variation to estimate the error accurately.

\begin{tabular}{cccc}
\hline \multicolumn{4}{c}{ Mean Average Soil Moisture by Neutron Probe } \\
\hline \multicolumn{4}{c}{ By Season } \\
\hline Season & Mix & None & Rye \\
\hline Cover Crop & $0.28(0.26,0.31)$ & $0.30(0.27,0.32)$ & $0.32(0.30,0.34)$ \\
Cotton & $0.21(0.20,0.23)$ & $0.23(0.21,0.24)$ & $0.24(0.22,0.26)$ \\
\hline & & By Month & Rye \\
\hline Month & Mix & None & $0.32(0.29,0.34)$ \\
\hline Feb. & $0.28(0.26,0.31)$ & $0.29(0.27,0.32)$ & $0.33(0.31,0.35)$ \\
Mar. & $0.29(0.27,0.31)$ & $0.31(0.28,0.33)$ & $0.31(0.29,0.34)$ \\
Apr. & $0.28(0.26,0.30)$ & $0.29(0.27,0.31)$ & $0.25(0.23,0.27)$ \\
Jul. & $0.21(0.19,0.23)$ & $0.22(0.20,0.23)$ & $0.23(0.21,0.24)$ \\
Aug. & $0.21(0.19,0.22)$ & $0.23(0.21,0.24)$ & $0.20(*)$ \\
Sep. & $0.19(*)$ & $0.21(*)$ & \\
\hline
\end{tabular}


(a) Mean Average Soil Moisture by Season

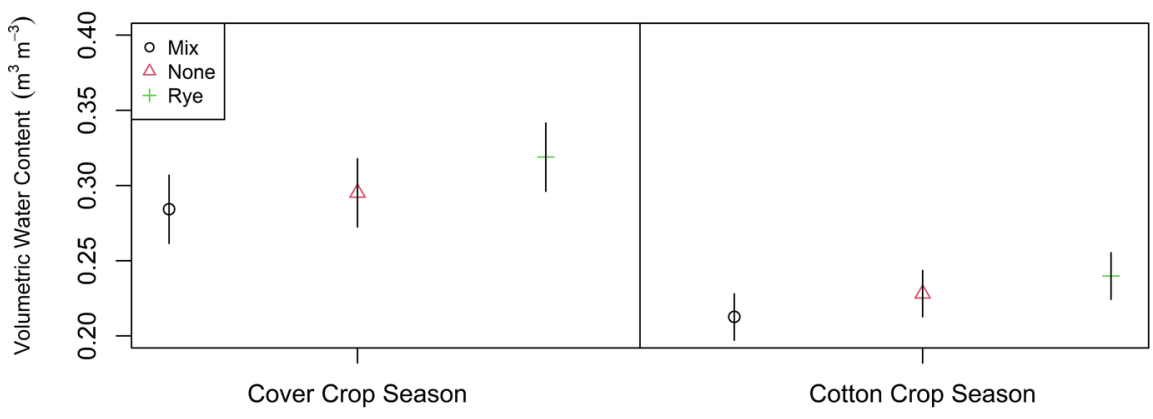

(b) Mean Average Soil Moisture by Month

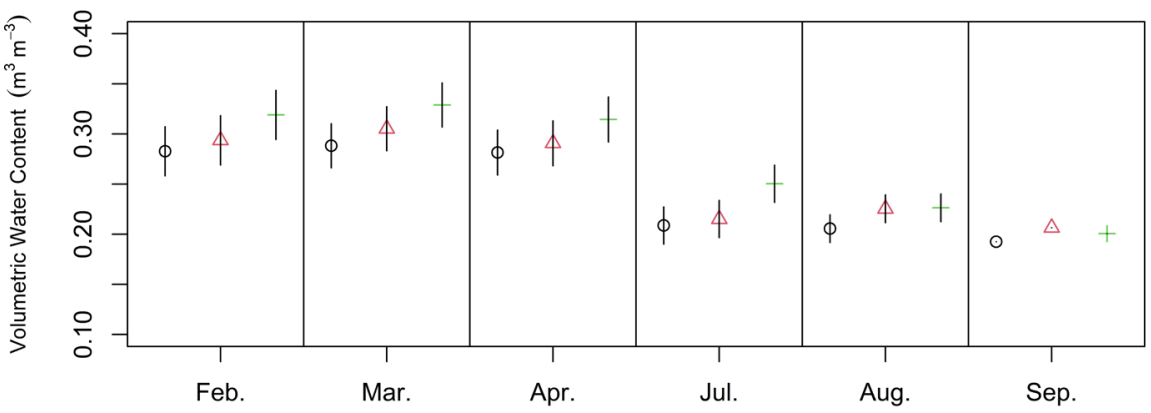

Figure 6. Mean average soil moisture with corresponding 95\% confidence intervals as measured by neutron probe. Means are presented stratifying by month and cover crop season (note that May was excluded due to cotton crop planting, and there were no neutron probe measurements in June).

(a) Total Biomass

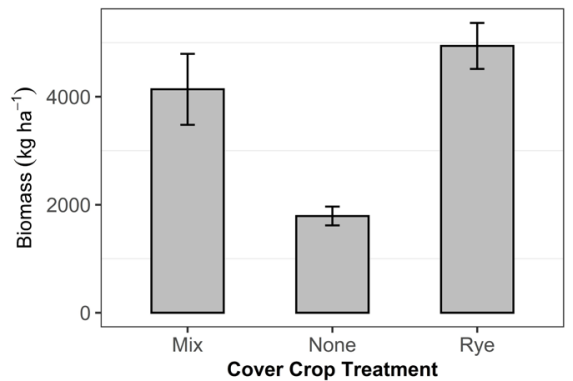

(b) Mix Treatment

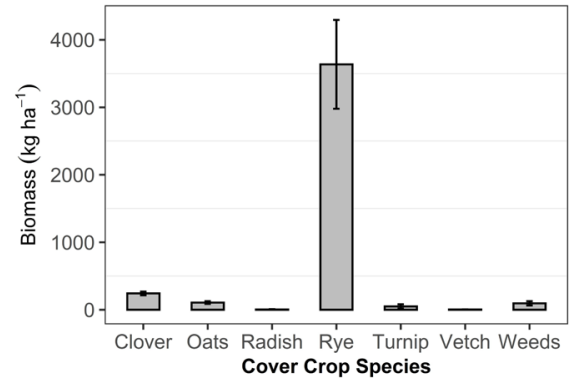

Figure 7. (a) Total biomass produced by cover crop treatment measured on $4 / 23 / 15$, and (b) Biomass produced by each cover crop species in the Mix treatment.

but the control treatment produced significantly less biomass than the other two treatments. Still, the control treatment without cover crop (None) produced a considerable amount of biomass from weeds. The production of weeds is a problem for farmers since they must be controlled before crop planting. The amount of biomass produced by the Mix and Rye cover crops provides mulch for the cash crop. The mulch could have potential benefits to the soils and cash crop, such as increasing soil organic carbon and carbohydrates, supplying soil 
Nitrogen, stabilizing soil temperature, suppressing weeds, reducing runoff and soil erosion, among other benefits [2] [3] [4] [5] [8] [11]. Figure 7(b) shows the different species' biomass in the Mix treatment, which indicates that the rye species predominated. There were insignificant amounts of biomass produced by all the other species. These results suggest that the percentage of rye seeds in the seed mixture should be reduced considerably to allow the other cover crop species in the mixture to grow.

\subsubsection{Cotton Yield Production}

The mean yield was $1259 \mathrm{~kg} / \mathrm{ha}(95 \%$ CI 836, 1682) for the Mix cover crop treatment, $1066 \mathrm{~kg} / \mathrm{ha}(95 \%$ CI 700,1433$)$ for the no cover crop (None) treatment, and $1132 \mathrm{~kg} / \mathrm{ha}(95 \%$ CI 766, 1499) for the Rye cover crop treatment. The cotton yield analysis showed no significant differences between the mean yields among the three cover crop treatments (Figure 8).

\subsection{Impact of Rainfall on Cover Crop Treatment Effect}

The daily and cumulative rain during 2015 at the study site are shown in Figure 9 , and the monthly rainfall totals are shown in Table 3 . Figure 9 showed frequent rain during 2015, totaling $1315 \mathrm{~mm}$, which was greater than the long-term average for the site (1198 $\mathrm{mm}$ per year). Rainfall during the cover crop growing period (January to April) averaged $112 \mathrm{~mm} /$ month. Also, there was significant rain $(118 \mathrm{~mm})$ in April, which replenished the soil profile just before the cover crop was terminated. Therefore, the soil profile was relatively saturated during the cover crop period, negating the cover crop potential effect on soil water. Although there was little rain in May $(10 \mathrm{~mm})$, there was significant rain in early June $(95 \mathrm{~mm})$, after the cotton crop was planted, which refilled the soil profile and counteracted any potential carry-over effect of the cover crop on soil water.

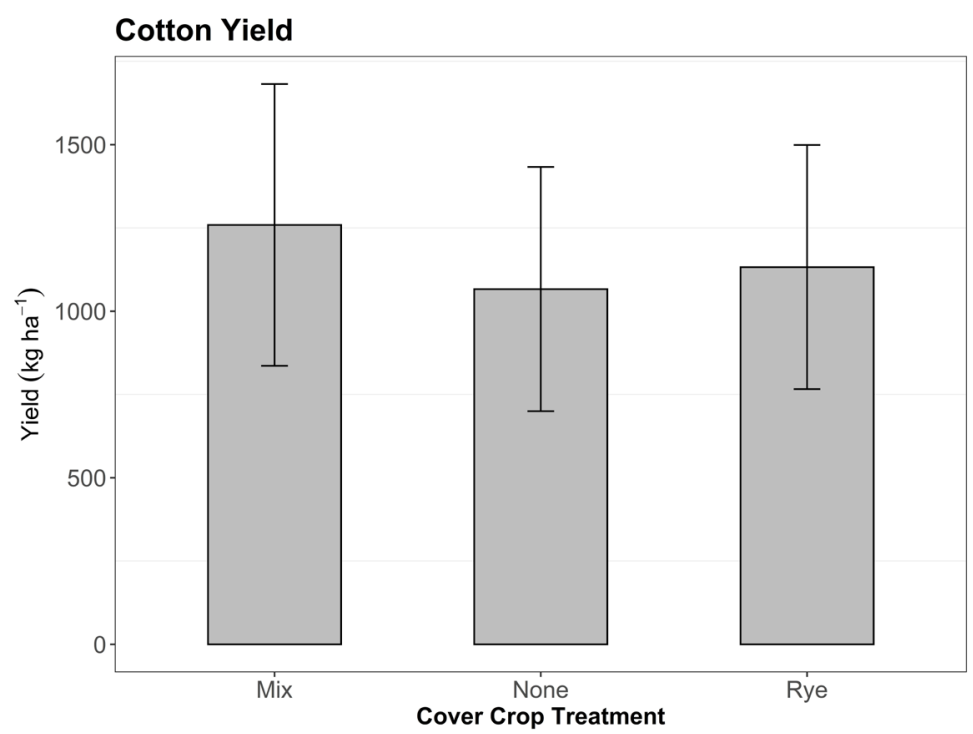

Figure 8. Cotton mean yield and corresponding 95\% confidence intervals by cover crop treatment. 
(a) Daily Rain

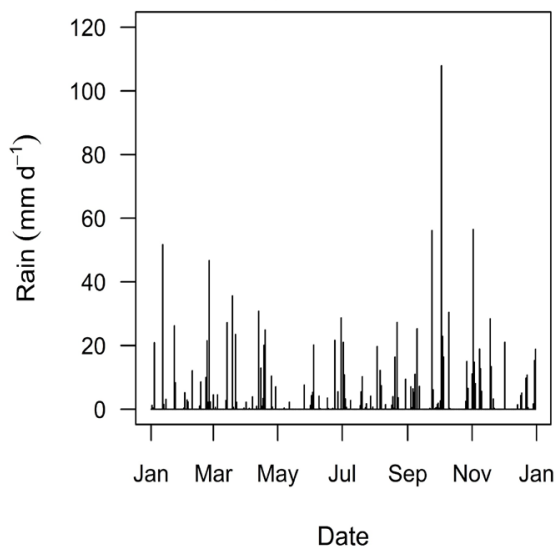

(b) Cumulative Rain

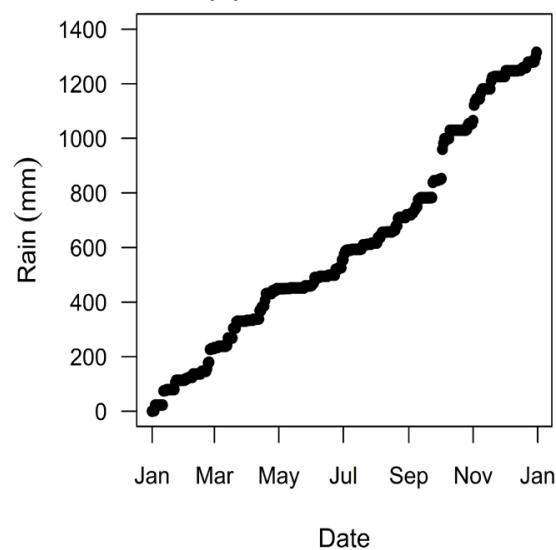

Figure 9. Daily and cumulative rainfall during 2015 in Blackville, SC.

Table 3. Monthly rain (mm) during 2015 in Blackville, SC.

\begin{tabular}{ccccccccccccc}
\hline Jan & Feb & Mar & Apr & May & Jun & Jul & Aug & Sept & Oct & Nov & Dec & Total \\
\hline 113 & 115 & 102 & 118 & 10 & 95 & 62 & 103 & 129 & 205 & 173 & 89 & 1315 \\
\hline
\end{tabular}

Several rain events in early July also contributed to replenish the soil profile during the early portion of the cotton-growing season. The impact of these rainfall events on soil VWC can be observed in Figure 4. These timely rainfall events offer some explanation as to why there was no significant effect of the cover crop treatments on soil water, neither during the cover crop season nor during the cotton season. It also demonstrates why there was no treatment effect on cotton yield.

\section{Conclusion}

In this experiment, Rye, Mix, and control (None) cover crop treatments were compared to evaluate their effects on soil water during both the cover crop growing season and the cotton-growing season. We also assessed the impact of the cover crop treatments on cover crop biomass production and cotton yield. Time series data of VWC were collected hourly using automatic capacitance soil moisture probes installed at four soil depths. Also, less frequent measurements were taken using a neutron probe. Our results showed that under the conditions of this study, the cover crop treatments had no significant effect on soil water. Also, the cover crop treatments did not affect cotton yield. However, the two cover crop treatments (Mix and Rye) provided a significant amount of biomass compared to the control, potentially offering additional benefits to the soil and the cash crop. The timely and abundant rain observed in this study masked any potential effect of the cover crop on soil water during the study. In this study, the cover crop had no detrimental impact on reducing soil water for the cash crop; however, there are many other beneficial aspects that the cover crop provides for the cash crop including weed suppression and nutrient recycling. 


\section{Acknowledgements}

Technical Contribution No. 6980 of the Clemson University Experiment Station. This material is based upon work supported by NIFA/USDA, under project SC-1700593 and SC-170539. Additional funding provided by USDA-NRCS Project number 69-3A75-17-274. Names of commercial products are solely provided as information to the reader and do not imply an endorsement or recommendation by the authors or their organizations.

\section{Conflicts of Interest}

The authors declare no conflicts of interest regarding the publication of this paper.

\section{References}

[1] Kuo, S., Sainju, U.M. and Jellum, E.J. (1997) Winter Cover Crop Effects on Soil Organic Carbon and Carbohydrate in Soil. Soil Science Society of American Journal, 61, 145-152. https://doi.org/10.2136/sssaj1997.03615995006100010022x

[2] Decker, A.M., Clark, A.J., Meisinger, J.J., Mulford, F.R. and Mclntosh, M.S. (1994) Legume Cover Crop Contributions to No-Tillage Corn Production. Agronomy Journal, 86, 126-135. https://doi.org/10.2134/agronj1994.00021962008600010024x

[3] Stipešević, B. and Kladivko, E.J. (2005) Effects of Winter Wheat Cover Crop Desiccation Times on Soil Moisture, Temperature and Early Maize Growth. Plant Soil Environment, 51, 255-261. https://doi.org/10.17221/3583-PSE

[4] Liebl, R., Simmons, F.W., Wax, L.M. and Stoller, E.W. (1992) Effect of Rye (Secale cereale) Mulch on Weed Control and Soil Moisture in Soybean (Glycine max). Weed Technology, 6, 838-846. https://doi.org/10.1017/S0890037X00036356

[5] Wells, M.S., Reberg-Horton, S.C. and Mirsky, S.B. (2014) Cultural Strategies for Managing Weeds and Soil Moisture in Cover Crop Based No-Till Soybean Production. Weed Science, 62, 501-511. https://doi.org/10.1614/WS-D-13-00142.1

[6] Clark, A.J., Decker, A.M., Meisinger, J.J. and Mcintosh, M.S. (1997) Kill Date of Vetch, Rye, and a Vetch-Rye Mixture: II. Soil Moisture and Corn Yield. Agronomy Journal, 89, 434-441. https://doi.org/10.2134/agronj1997.00021962008900030011x

[7] Mitchell, J.P., Shrestha, A. and Irmak, S. (2015) Trade-Offs Between Winter Cover Crop Production and Soil Water Depletion in the San Joaquin Valley, California. Journal of Soil and Water Conservation, 70, 430-440. https://doi.org/10.2489/jswc.70.6.430

[8] Ruiz-Colmenero, M., Bienes, R. and Marques, M.J. (2011) Soil and Water Conservation Dilemmas Associated with the Use of Green Cover in Steep Vineyards. Soil \& Tillage Research, 117, 211-223. https://doi.org/10.1016/j.still.2011.10.004

[9] Yang, W., Feng, G., Adeli, A., Kersebaum, K.C., Jenkins, J.N. and Li, P. (2019) Long-Term Effect of Cover Crop on Rainwater Balance Components and Use Efficiency in the No-Tilled and Rainfed Corn and Soybean Rotation System. Agricultural Water Management, 219, 27-39. https://doi.org/10.1016/j.agwat.2019.03.022

[10] Karukua, G.N., Gachenea, C.K.K., Karanjaa, N., Cornelisb, W. and Verplacke, H. (2014) Effect of Different Cover Crop Residue Management Practices on Soil Moisture Content under a Tomato Crop (Lycopersicon esculentum). Tropical and Subtropical Agroecosystems, 17, 509-523. 
[11] Acharya, B.S., Dodla, S., Gaston, L.A., Darapuneni, M., Wang, J.J., Sepat, S. and Bohara, H. (2019) Winter Cover Crops Effect on Soil Moisture and Soybean Growth and Yield under Different Tillage Systems. Soil \& Tillage Research, 195, 104430. https://doi.org/10.1016/j.still.2019.104430

[12] Clark, A.J., Meisinger, J.J., Decker, A.M. and Mulford, F.R. (2007) Effects of a Grass-Selective Herbicide in a Vetch-Rye Cover Crop System on Corn Grain Yield and Soil Moisture. Agronomy Journal, 99, 43-48.

https://doi.org/10.2134/agronj2005.0362

[13] Daigh, A.L., Helmers, M.J., Kladivko, E., Zhou, X., Goeken, R., Cavdini, J., Barker, D. and Sawyer, J. (2014) Soil Water during the Drought of 2012 as Affected by Rye Cover Crops in Fields in Iowa and Indiana. Journal of Soil and Water Conservation, 69, 564-573. https://doi.org/10.2489/jswc.69.6.564

[14] McGuire, A.M., Bryant, D.C. and Denison, R.F. (1998) Wheat Yields, Nitrogen Uptake, and Soil Moisture Following Winter Legume Cover Crop vs. Fallow. Agronomy Journal, 90, 404-410. https://doi.org/10.2134/agronj1998.00021962009000030015x

[15] Kahimba, F.C., Sri Ranjan, R., Froese, J., Entz, M. and Nason, R. (2008) Cover Crop Effects on Infiltration, Soil Temperature, and Soil Moisture Distribution in the Canadian Prairies. Applied Engineering in Agriculture, 24, 321-333. https://doi.org/10.13031/2013.24502

[16] Krueger, E.S., Ochsner, T.E., Porter, P.M. and Baker, J.M. (2011) Winter Rye Cover Crop Management Influences on Soil Water, Soil Nitrate, and Corn Development. Agronomy Journal, 103, 316-323. https://doi.org/10.2134/agronj2010.0327

[17] Meyer, N., Bergez, J., Constantin, J., Belleville, P. and Justes, E. (2020) Cover Crops Reduce Drainage but not Always Soil Water Content Due to Interactions Between Rainfall Distribution and Management. Agricultural Water Management, 231, 105998. https://doi.org/10.1016/j.agwat.2019.105998

[18] USDA-NRCS (2020) Web Soil Survey. United States Department of Agriculture (USDA), Natural Resources Conservation Service (NRCS). https://websoilsurvey.sc.egov.usda.gov/App/WebSoilSurvey.aspx

[19] Your Weather Service (2021) U.S. Climate Data. https://www.usclimatedata.com/climate/blackville/south-carolina/united-states/ussc $\underline{0025}$

[20] Visvalingam, M. and Tandy, J.D. (1972) The Neutron Method for Measuring Soil Moisture Content-A Review. The Journal of Soil Science, 23, 499-511. https://doi.org/10.1111/j.1365-2389.1972.tb01680.x

[21] R Core Team (2020) R: A Language and Environment for Statistical Computing. R Foundation for Statistical Computing, Vienna. https://www.R-project.org/ 